\title{
Ligand for Translocator Protein Reverses Pathology in a Mouse Model of Alzheimer's Disease
}

\author{
Anna M. Barron, ${ }^{1,2}$ Luis M. Garcia-Segura, ${ }^{3}$ Donatella Caruso, ${ }^{4}$ Anusha Jayaraman, ${ }^{1}$ Joo-Won Lee, ${ }^{1}$ \\ Roberto C. Melcangi, ${ }^{4}$ and Christian J. Pike ${ }^{1}$ \\ ${ }^{1}$ Davis School of Gerontology, University of Southern California, Los Angeles, California 90089, ${ }^{2}$ Molecular Imaging Center, National Institute of \\ Radiological Sciences, Chiba 263-8555, Japan, ${ }^{3}$ Instituto Cajal, CSIC, E-28002 Madrid, Spain, and ${ }^{4}$ Department of Pharmacological and Biomolecular \\ Sciences, Center of Excellence on Neurodegenerative Diseases, University of Milan, 20133 Milan, Italy
}

Ligands of the translocator protein (TSPO) elicit pleiotropic neuroprotective effects that represent emerging treatment strategies for several neurodegenerative conditions. To investigate the potential of TSPO as a therapeutic target for Alzheimer's disease (AD), the current study assessed the effects of the TSPO ligand Ro5-4864 on the development of neuropathology in 3xTgAD mice. The effects of the TSPO ligand on neurosteroidogenesis and AD-related neuropathology, including $\beta$-amyloid accumulation, gliosis, and behavioral impairment, were examined under both early intervention (7-month-old young-adult male mice with low pathology) and treatment (24month-old, aged male mice with advanced neuropathology) conditions. Ro5-4864 treatment not only effectively attenuated development of neuropathology and behavioral impairment in young-adult mice but also reversed these indices in aged 3xTgAD mice. Reduced levels of soluble $\beta$-amyloid were also observed by the combination of TSP0 ligands Ro5-4864 and PK11195 in nontransgenic mice. These findings suggest that TSPO is a promising target for the development of pleiotropic treatment strategies for the management of AD.

\section{Introduction}

Ligands of translocator protein (TSPO), a mitochondrial molecule involved in the control of steroidogenesis (Papadopoulos et al., 2006b), elicit pleiotropic neuroprotective effects, promoting nerve regeneration while reducing oxidative damage, apoptosis, and gliosis (Rupprecht et al., 2010). Increased neurosteroid synthesis is perhaps the best characterized effect of TSPO ligands and most likely contributes at least in part to the plethora of established neuroprotective actions and anxiolytic and antidepressant behavioral effects (Rupprecht et al., 2010). Consequently, TSPO ligands are under investigation for use in the treatment of a range of neurological disorders, including traumatic brain injury (Papadopoulos and Lecanu, 2009), peripheral neuropathies (Giatti et al., 2009), inflammatory conditions (Veiga et al., 2005), chronic pain (Torres et al., 2000), depression (Gavioli et al., 2003), and anxiety (Rupprecht et al., 2009). Although potential therapeutic applications of TSPO ligands to Alzheimer's disease (AD) have been suggested (Veenman and Gavish, 2000; Papadopoulos et al., 2006a), to date AD-related investigations of

\footnotetext{
Received March 20, 2013; accepted April 11, 2013.

Author contributions: A.M.B., A.J., J.-W.L., and C.J.P. designed research; A.M.B., L.M.G.-S., D.C., A.J., J.-W.L., and R.C.M. performed research; A.M.B., L.M.G.-S., D.C., A.J., J.-W.L., R.C.M., and C.J.P. analyzed data; A.M.B. and C.J.P. wrote the paper.

This study was supported by National Institutes of Health Grant AG05142 to C.J.P. A.M.B. was supported by the American-Australian Association and the Japan Society for the Promotion of Science. R.C.M. was supported by Fondazione San Paolo (Progetto Neuroscienze, PF-2009.1180).

The authors declare no competing financial interests.

Correspondence should be addressed to Dr. Christian J. Pike, Davis School of Gerontology, University of Southern California, 3715 McClintock Avenue, Los Angeles, CA 90089. E-mail: cjpike@usc.edu.

DOI:10.1523/JNEUROSCI.1350-13.2013

Copyright $\odot 2013$ the authors $\quad 0270-6474 / 13 / 338891-07 \$ 15.00 / 0$
}

TSPO ligands have assessed only their utility in detecting gliosis via in vivo $\mathrm{PET}$ imaging in $\mathrm{AD}$ patients and mouse models of $\mathrm{AD}$ (Edison et al., 2008; Ji et al., 2008; Yasuno et al., 2008).

Although the mechanisms of $\mathrm{AD}$ pathogenesis remain to be fully resolved, the leading hypothesis posits that the disease is initiated and driven by prolonged elevation in levels of $\beta$-amyloid protein $(\mathrm{A} \beta)$ (Walsh and Selkoe, 2007). Despite enormous effort to develop therapies that specifically reduce $A \beta$ accumulation, thus far these strategies have proven unsuccessful clinically. TSPO ligands may offer an alternative to specific $\mathrm{A} \beta$-regulating strategies in that they simultaneously target multiple facets of the neurodegenerative cascade, perhaps including not only $\mathrm{A} \beta$ accumulation but also aspects of neuroinflammation, oxidative stress, mitochondrial dysfunction, and neuronal loss (Rupprecht et al., 2010).

To investigate the potential of TSPO as a therapeutic target for $\mathrm{AD}$, the current study assessed the effects of TSPO ligand Ro54864 in the 3xTgAD mouse model of AD (Oddo et al., 2003). The effects of Ro5-4864 on neurosteroidogenesis and AD-related neuropathology, including $\mathrm{A} \beta$ accumulation, gliosis, and behavioral impairment, were assessed in both young-adult 3xTgAD mice with mild pathology and aged 3xTgAD mice with advanced neuropathology, allowing insight into protective actions under early versus late intervention scenarios. Because TSPO ligands can differentially modulate TSPO activities, we also compared the independent and combined effects of Ro5-4864 with PK11195 , a nonbenzodiazepine TSPO ligand, on regulation of A $\beta$ levels in nontransgenic (non-Tg) mice.

\section{Materials and Methods}

Animals and treatments. Male homozygous 3xTgAD and non-Tg C57BL/6 mice (The Jackson Laboratory) were maintained at the Univer- 
sity of Southern California vivarium facilities with food and water available ad libitum. In experiments with young-adult mice, males (age 4 months) were gonadectomized (GDX) to deplete gonadal sources of sex hormones and preclude TSPO-ligand upregulation of steroidogenesis in the testes. In studies with young-adult 3xTgAD mice, GDX and sham-GDX mice were divided into three groups $(N=7-10 /$ group $)$ : sham + vehicle, GDX + vehicle, and GDX + Ro5-4864; and administered Ro5-4864 (3 $\mathrm{mg} / \mathrm{kg}$ ) or vehicle (1\% DMSO in canola oil) by injection (i.p.) once weekly for 3 months. This dose of Ro5-4864 has been widely used to yield neuroprotective effects in vivo (Veiga et al., 2005; Giatti et al., 2009). In experiments with aged $3 \times \mathrm{XTgAD}$ mice, males (age 23 months, $N=$ 6/group) were similarly injected with Ro5-4864 or vehicle for 4 weeks. In studies with non-Tg C57BL/6 mice, males were GDX or sham-GDX at age 3 months and then assigned to one of the following groups ( $N=6$ or 7/group): sham + vehicle, GDX + vehicle, GDX + Ro5-4864, GDX + PK-11195, or GDX + PK-11195 + Ro5-4864. Treatments of either vehicle, Ro5-4864 (3 mg/kg) or PK-11195 (3 mg/kg), were administered via once weekly injection (i.p.) beginning 2 weeks after surgery and continuing for 4 weeks. Mice were anesthetized $(80 \mathrm{mg} / \mathrm{kg}$ ketamine $/ 5 \mathrm{mg} / \mathrm{kg}$ xylazine; i.p.) and perfused with ice-cold saline $48 \mathrm{~h}$ after the final injection. Brains were bisected, with one hemisphere immersion fixed in $4 \%$ paraformaldehyde/0.1 M PBS for $48 \mathrm{~h}$ and the limbic regions of the other hemisphere frozen on dry ice for neurosteroid assessment. All experiments were approved by the University of Southern California Institutional Animal Care and Use Committee.

Immunohistochemistry. Fixed hemibrains were sectioned exhaustively in the horizontal plane at $40 \mu \mathrm{m}$. Some sections were labeled using antibodies directed against $\mathrm{A} \beta$ (\#71-58000, 1:300 dilution; Zymed) or hyperphosphorylated tau (AT8, 1:1000 dilution; Pierce Chemical) using a standard avidin: biotinylated enzyme complex immunoperoxidase method as previously described (Rosario, 2006). A $\beta$-immunoreactive load was calculated as percentage of total pixel area positively labeled in binary images created by thresholding digitally captured grayscale images of high-magnification fields $(420 \times 330 \mu \mathrm{m})$ as previously described (Cummings et al., 2002). Mean load values were averaged from two or three nonoverlapping fields from each brain region in five sections per animal. AT8 immunoreactivity was quantified by counting cells strongly immunoreactive over the entire cell surface, as previously described (Carroll et al., 2010).

Other sections were labeled using antibodies directed against ionized calcium binding adaptor molecule-1 (IBA-1, Wako Chemicals) as a marker of microglial activation (Ito et al., 1998) or GFAP (clone GA5; Sigma-Aldrich) as a marker of astrocyte reactivity (Middeldorp and Hol, 2011), as previously described (Barreto et al., 2009). IBA-1 and GFAP immunoreactivities were quantified by volume density morphometric analysis (Weibel, 1979). Experimenters were blinded to treatment conditions during quantification.

Behavioral testing procedures. Anxiety and exploratory activity were assessed in the elevated plus maze (EPM), and spontaneous alternation behavior ( $\mathrm{SAB})$ was assessed in the Y-maze, as previously described (Carroll et al., 2010). Mice were tested in the EPM $24 \mathrm{~h}$ after the fourth injection. The total number of arm entries was scored as a marker of exploratory activity, and duration spent exploring the open arm was scored as an index of anxiety-related behavior. After a $1 \mathrm{~h}$ interval, SAB was assessed. Arm choices were recorded, and the SAB score was calculated as the number of alternations divided by the total number of alternation opportunities. One outlier was excluded from analysis from the 7-month-old sham + vehicle group.

Liquid chromatography tandem mass spectrometry (LC-MS/MS) anal$y$ sis of neuroactive steroids. Samples were homogenized and purified by organic phase extraction for LC-MS/MS analysis as previously described (Caruso et al., 2008). The LC-MS/MS system consisted of a linear ion trap-mass spectrometer (LTQ, ThermoElectron) equipped with a Surveyor liquid chromatography (LC) Pump Plus and a Surveyor Autosampler Plus (ThermoElectron). Chromatographic separation was performed on a Inertsil ODS-2 RP-C18 column $(5 \mu \mathrm{m}, 150 \mathrm{~mm} \times 4.6$ mm i.d.; GL Sciences), and the MS was operated with atmospheric pressure chemical ionization in the positive ion mode. LC-MS/MS peaks were evaluated using Excalibur release 2.0 SR2 (ThermoFisher). Calibra- tion curves were prepared and analyzed using deuterated internal standards. Limits of quantification, precision, and accuracy have been previously reported (Caruso et al., 2008). One outlier was excluded from analysis of progesterone levels from the GDX + vehicle group.

$A \beta$ ELISA. Homogenates of hemibrains from non-Tg mice were prepared as previously described (Ramsden et al., 2003) and used to quantify levels of soluble $\mathrm{A} \beta \mathrm{x}-40$ and $\mathrm{A} \beta \mathrm{x}-42$ using commercially available ELISA kits according to the manufacturer's instructions (Wako).

Data analysis. Data were analyzed using the Statistical Package for Social Sciences (SPSS, version 11.5). The effect of GDX and Ro5-4864 administration in the young-adult 3xTgAD mice was assessed by oneway ANOVA followed by least-square difference tests. The effect of Ro54864 treatment in the aged-senescent $3 \times \mathrm{TgAD}$ mice was determined by $t$ tests. The effect of treatment on $\mathrm{A} \beta$ levels in $\mathrm{C} 57 \mathrm{BL} / 6$ mice was assessed by linear mixed model followed by least-square difference tests. Significance was set at a threshold of $p<0.05$. Data are mean \pm SEM.

\section{Results}

\section{Ro5-4864 attenuates hippocampal A $\beta$ accumulation in} 3xTgAD mice

In young-adult $3 \times \mathrm{TgAD}$ mice, a significant effect of treatment was observed on $\mathrm{A} \beta$-immunoreactive load in the hippocampal CA1 region $(F=4.53, p=0.02)$. GDX accelerated $\mathrm{A} \beta$ accumulation in hippocampus $C A 1$, increasing $A \beta$-immunoreactive load of vehicle-treated GDX mice compared with sham mice (Fig. $1 A, B, K)$. Ro5-4864 treatment attenuated $\mathrm{A} \beta$ accumulation in the $\mathrm{CA} 1$ region of GDX mice, with $\mathrm{A} \beta$ load almost halved in Ro5-4864 compared with vehicle-treated GDX mice (Fig. $1 B, C, K)$. A $\beta$ load in the subiculum was not significantly affected by either GDX (Fig. $1 F, G, L$ ) or Ro5-4864 administration (Fig. $1 G, H, L ; F=2.86, p=0.08)$. In aged 3xTgAD mice, Ro5-4864 treatment also decreased $\mathrm{A} \beta$ load in the hippocampus CA1 by $>50 \%(t=2.08, p=0.03$; Fig. $1 D, E, K)$. A trend toward decreased subiculum $A \beta$ load was noted in aged mice administered Ro5-4864; however, this did not reach significance $(t=1.70, p=$ 0.06; Fig. $1 I, J, L)$.

As an indicator of tau neuropathology, the number of cells immunoreactive with the phospho-specific tau antibody, AT8, was assessed in aged 3xTgAD mice. No significant difference in the number of AT8-immunoreactive neurons between vehicle $(58.3 \pm 15.3)$ and Ro5-4864 (40.8 \pm 17.3$)$ treated groups was observed $(t=0.76, p=0.23)$.

\section{Ro5-4864 decreases gliosis in 3xTgAD mice}

In young-adult 3xTgAD mice, significant effects of treatment were observed on both GFAP $(F=29.88, p<0.001)$ and IBA-1 $(F=39.60, p<0.001)$ hippocampal immunoreactivities. GDX was associated with modest but significant increases in hippocampal GFAP (Fig. 2A,B,K) and IBA-1 immunoreactivities (Fig. $2 F, G, L$ ). Ro5-4864 administration in GDX mice more than halved GFAP (Fig. $1 B, C, K$ ) and IBA-1 (Fig. 2G, H,L) immunoreactivities. Similarly, Ro5-4864 treatment strongly lowered $\operatorname{GFAP}(t=6.76, p<0.001$; Fig. $2 D, E, K)$ and IBA- $1(t=6.00, p<$ 0.001 ; Fig. $2 I, J, L)$ immunoreactivities in the aged $3 \mathrm{xTgAD}$ mice.

\section{Ro5-4864 alters brain testosterone and progesterone levels in 3xTgAD mice}

Because TSPO regulates synthesis of neuroactive steroids, we measured brain levels of several steroids. In young-adult $3 \times \mathrm{TgAD}$ mice, a significant effect of treatment was observed on testosterone $(F=5.43 p=0.02)$ and progesterone $(F=6.25, p=0.008)$ levels. GDX depleted brain levels of testosterone (Fig. $3 A$ ) and progesterone (Fig. 3B), whereas Ro5-4864 administration in GDX mice increased brain testosterone and progesterone com- 

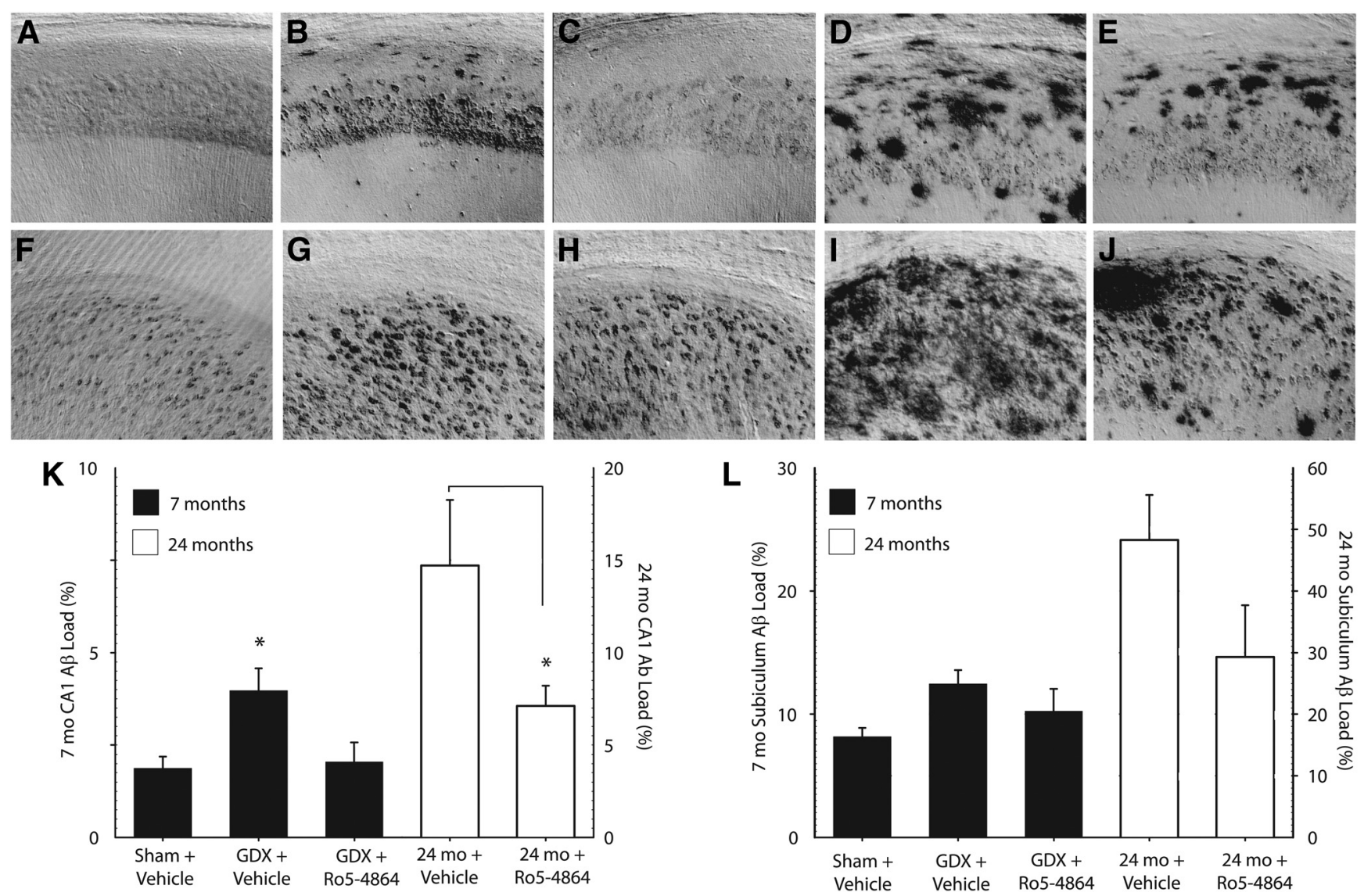

Figure 1. R05-4864 reduces $A \beta$ accumulation in the hippocampus of $3 \times T g A D$ mice. $A-J$, Representative photomicrographs show $A \beta$ immunoreactivity in hippocampus $C A 1(A-E)$ and subiculum $(\boldsymbol{F}-\boldsymbol{J})$ regions of 7-month-old 3xTgAD mice in the sham + vehicle $(\boldsymbol{A}, \boldsymbol{F}), \mathrm{GDX}+$ vehicle $(\boldsymbol{B}, \boldsymbol{G})$, and GDX + R05-4864 $(\boldsymbol{C}, \boldsymbol{H})$ conditions; and 24-month-0ld 3xTgAD mice administered vehicle $(\boldsymbol{D}$, I) and R05-4864 $(\boldsymbol{E}, J)$. Data show mean A $\beta$ immunoreactivity loads ( \pm SEM) in 3xTgAD mice at ages 7 months (solid bars, left axis) and 24 months (open bars, right axis) in hippocampus CA1 (K) and subiculum $(\boldsymbol{L}) .{ }^{*} p<0.05$, compared with all other groups.

pared with vehicle-treated GDX mice (Fig. $3 A, B)$. Brain levels of pregnenolone $(p=0.54)$, iso-pregnanolone $(p=0.25)$, dihydroprogesterone $(p=0.17)$, tetrahydroprogesterone $(p=0.60)$, $17 \beta$-estradiol $(p=0.15)$, and dihydrotestosterone $(p=0.97)$ were not significantly affected by Ro5-4864 treatment in GDX mice (data not shown).

Ro5-4864 administration did not significantly alter brain levels of testosterone $(t=-1.51, p=0.19$; Fig. $3 A)$ in aged $3 x T g A D$ mice; however, brain levels of progesterone $(t=4.15, p<0.01$; Fig. $3 B)$ and its metabolites were decreased: dihydroprogesterone $($ vehicle $=39.8 \pm 3.44 ; \operatorname{Ro5}-4864=20.0 \pm 3.51 ; t=3.96, p<0.01$ ), and tetrahydroprogesterone (vehicle $=1.7 \pm 0.50$; Ro5-4864 $=$ $0.2 \pm 0.09 ; t=2.54, p<0.05)$. Brain pregnenolone $(p=0.27)$, iso-pregnanolone $(p=0.18), \mathrm{E} 2(p=0.14)$, and dihydrotestosterone $(p=0.34)$ levels were not significantly changed after Ro5-4864 treatment in the aged mice (data not shown).

\section{Ro5-4864 improves behavioral measures in 3xTgAD mice}

In young-adult $3 \times T$ TgAD mice, anxiety-related behavior in the EPM was significantly affected by treatment $(F=6.86, p=$ $0.006)$. GDX increased anxiety-related behavior, with GDX mice spending significantly less time exploring the open arms of the EPM compared with sham-GDX mice (Fig. 3C). A trend toward decreased anxiety-related behavior was observed in Ro5-4864treated mice, with a nonsignificant increase in duration spent exploring the open arm compared with vehicle-treated GDX mice $(p=0.054)$. In the aged 3xTgAD mice, Ro5-4864 treatment was associated with decreased anxiety, with Ro5-4864-treated mice spending more time exploring the open arms of the EPM $(t=2.13, p=0.03)$. No significant effect of treatment was observed on the number of arm entries in either the young-adult or aged mice, suggesting no effect of treatment on exploratory activity.

$\mathrm{SAB}$ in the Y-maze, a hippocampal-dependent measure of working memory and attention (Lalonde, 2002), was also significantly affected by treatment in the young-adult mice $(F=8.69$, $p=0.002$ ). The GDX group exhibited significantly impaired SAB compared with sham GDX mice (Fig. 3D). Significantly improved SAB performance was observed in GDX mice treated with Ro5-4864 compared with vehicle-treated GDX mice. Ro5-4864 treatment also significantly improved $S A B$ performance in aged $3 \mathrm{xTgAD}$ mice compared with vehicle-treated controls $(t=2.08$, $p=0.03)$.

\section{Combined Ro5-4864 and PK-11195 treatment reduces $A \beta$ in non-Tg mice}

There are several known TSPO ligands that differentially activate TSPO. To begin investigating how other TSPO ligands affect ADrelated pathologies, we compared Ro5-4864 with PK-11195, a nonbenzodiazepine TSPO ligand, for $\mathrm{A} \beta$-lowering actions in non-Tg male mice. A $\beta$-40 levels were significantly affected by TSPO ligand treatments in non-Tg mice $(F=4.33, p=0.003$; Fig. $4 A)$. Ro5-4864 reduced A $\beta-40$ levels $\sim 15 \%$ compared with GDX mice $(p<0.02)$. Although mean $\mathrm{A} \beta-40$ levels were $\sim 10 \%$ lower 

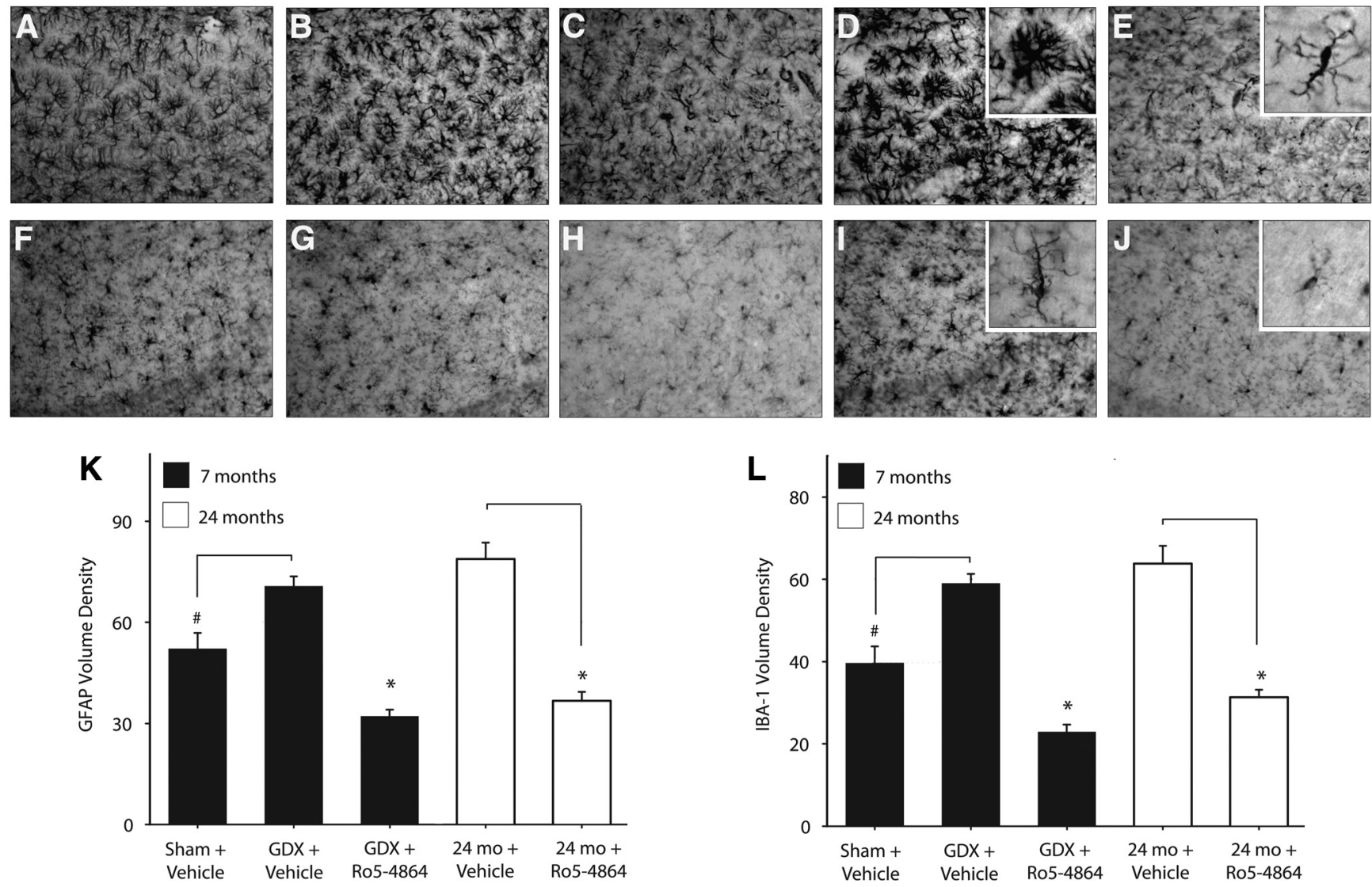

Figure 2. R05-4864 reduces hippocampal gliosis in 3xTgAD mice. $\boldsymbol{A}-\boldsymbol{J}$, Representative photomicrographs show GFAP $(\boldsymbol{A}-\boldsymbol{E})$ and IBA-1 (F-J) immunoreactivities in the hippocampus $C A 1$ region of 7-month-old 3xTgAD mice in the sham + vehicle $(\boldsymbol{A}, \boldsymbol{F}), \mathrm{GDX}+$ vehicle $(\boldsymbol{B}, \boldsymbol{G})$, and GDX + R05-4864 $(\boldsymbol{C}, \boldsymbol{H})$ conditions; and 24-month-old 3xTgAD mice administered vehicle (D, $\boldsymbol{I})$ and Ro5-4864 $(\boldsymbol{E}, J) . \boldsymbol{K}, \mathrm{GFAP}$ immunoreactivity volume density values ( \pm SEM) in the hippocampus $\left(A 1\right.$ region. $L$, IBA-1 immunoreactivity volume density values ( \pm SEM) in the hippocampus $C A 1$ region. ${ }^{\#} p<$ 0.001 , compared with GDX + vehicle. ${ }^{*} p<0.001$, compared with all other groups.

in PK-11195-treated compared with GDX mice, this was not significantly different compared with either vehicle or Ro5-4864treated groups. Coadministration of Ro5-4864 and PK-11195 had an additive effect, decreasing $A \beta-40$ levels by $>25 \%$ compared with vehicle-treated GDX mice $(p<0.001)$. A $\beta$-40 levels in Ro5-4864 + PK-11195-treated mice were significantly reduced compared with even sham-operated mice $(p<0.02)$. A similar but nonsignificant trend was observed for TSPO ligand treatments on $\mathrm{A} \beta-42$ levels $(F=2.33, p=0.061$; Fig. $4 B)$.

\section{Discussion}

TSPO ligands have been found to be neuroprotective after a wide range of insults, including peripheral nerve injury (e.g., Giatti et al., 2009), traumatic brain injury (for review, see Papadopoulos and Lecanu, 2009), excitotoxic lesion (e.g., Veiga et al., 2005), and inflammatory insult (e.g., Torres et al., 2000). Our findings suggest that TSPO may also be a promising target for the development of therapeutics for the treatment of $\mathrm{AD}$. We observe that TSPO ligands not only reduce the development of AD-related neuropathology in young-adult non-Tg and 3xTgAD mice but also reverse pathology and improve cognition in aged 3xTgAD mice.

Increased neurosteroidogenesis is an established mechanism of action of TSPO ligands. Prior observations that neurosteroid levels are altered in both normal aging and $\mathrm{AD}$ in humans (Yue et al., 2005; Rosario et al., 2011), 3xTg-AD mice (Caruso et al., 2013), and non-Tg rodents (Vallee et al., 1997) suggest that regulation of neurosteroids may contribute to the observed protec- tion. Consistent with this possibility, prior studies have shown that testosterone (Rosario et al., 2010), dihydrotestosterone (Rosario, 2006), progesterone (Carroll et al., 2010), and the progesterone metabolite allopregnanolone (Chen et al., 2011) attenuate $\mathrm{A} \beta$ accumulation and improve memory deficits in $3 \mathrm{xTgAD}$ mice. In the current study, Ro5-4864 increased both testosterone and progesterone in young-adult 3xTgAD mice. However, the absence of similar regulation of neurosteroids by Ro5-4864 in aged $3 x T g A D$ mice suggests that either neurosteroid regulation is not essential to the $\mathrm{A} \beta$-lowering actions of TSPO ligands or that the primary protective mechanism(s) of TSPO ligands differs in young versus aged mice. Elevated levels of additional neurosteroids, including pregnenolone and DHT, have also been observed in response to Ro5-4864 in other rodent paradigms (Giatti et al., 2009). Although it is unclear why different patterns of neurosteroid regulation are observed across studies, the spectrum of neurosteroids induced by TSPO ligands and the magnitude of these effects likely depend upon a variety of experimental parameters, including brain region, duration of TSPO ligand treatment, and latency between treatment and tissue collection.

Another important mechanism contributing to neuroprotective actions of TSPO ligands is reduction of gliosis and its associated proinflammatory effects. We observed strong morphological evidence of decreased astrocytic and microglial activation in young and aged 3xTgAD mice with Ro5-4864. Although the marked reduction in gliosis may have been a downstream result of reduced $\mathrm{A} \beta$ accumulation, previous studies have 


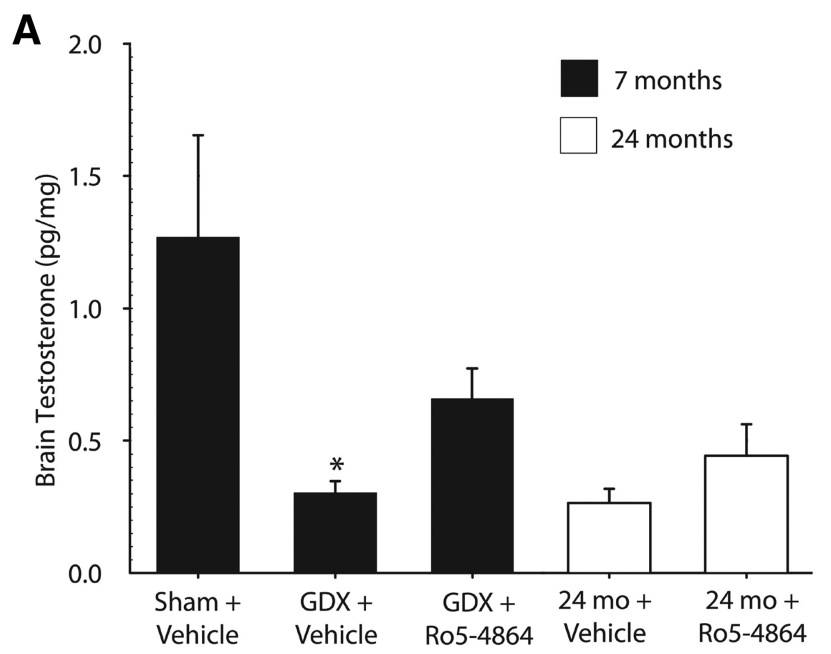

C

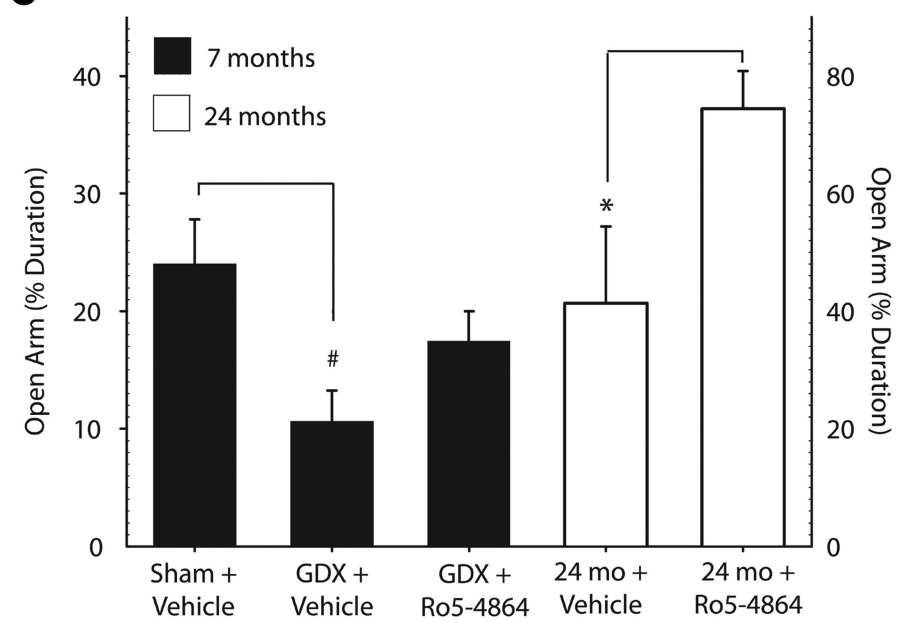

B

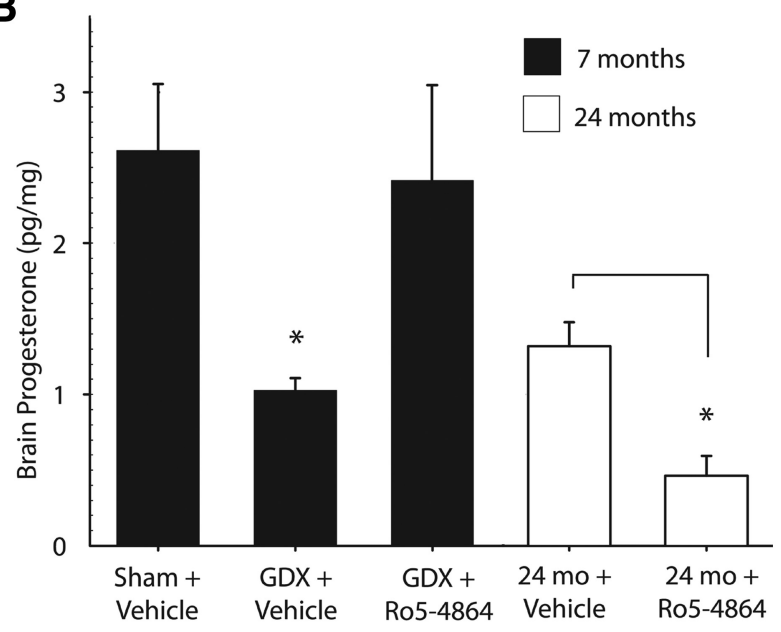

D

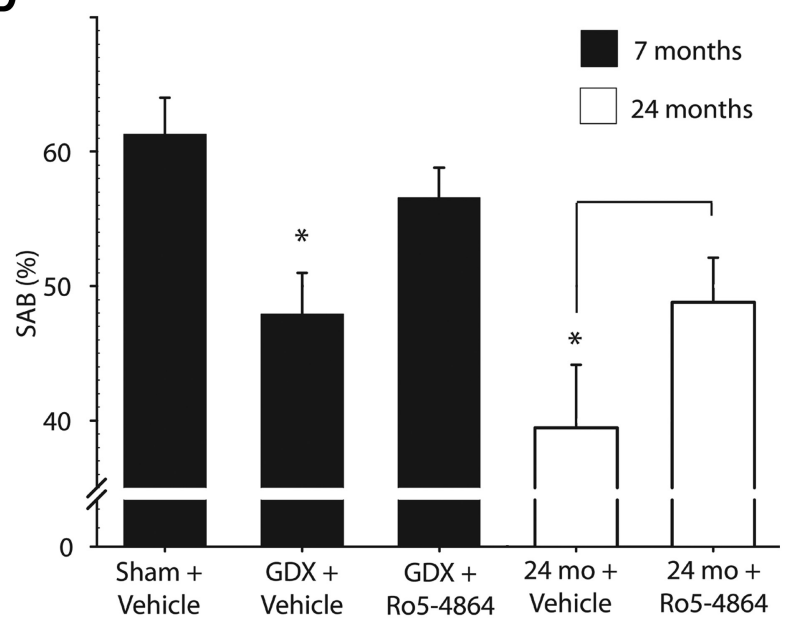

Figure 3. R05-4864 regulates brain testosterone and progesterone levels and improves behavioral deficits in 3XTgAD mice. $A$, Brain testosterone levels were quantified in limbic structures. Ro5-4864 treatment attenuated GDX-induced testosterone depletion in young-adult 7-month-old mice. B, Brain progesterone levels were quantified in limbic structures. R05-4864 treatment increased PROG more than twofold in GDX 7-month-old mice. C, Percentage duration ( \pm SEM) spent exploring the open arm of the EPM, with increased exploration of the open arm indicative of reduced anxiety. $\boldsymbol{D}, S A B$, represented as percentage alternation ( \pm SEM); both 7-month-old GDX and 24-month-old 3xTgAD mice administered R05-4864 exhibited significantly improved SAB performance. ${ }^{\#} p<0.05$, compared with sham + vehicle. ${ }^{*} p<0.05$, compared with all other groups.

A

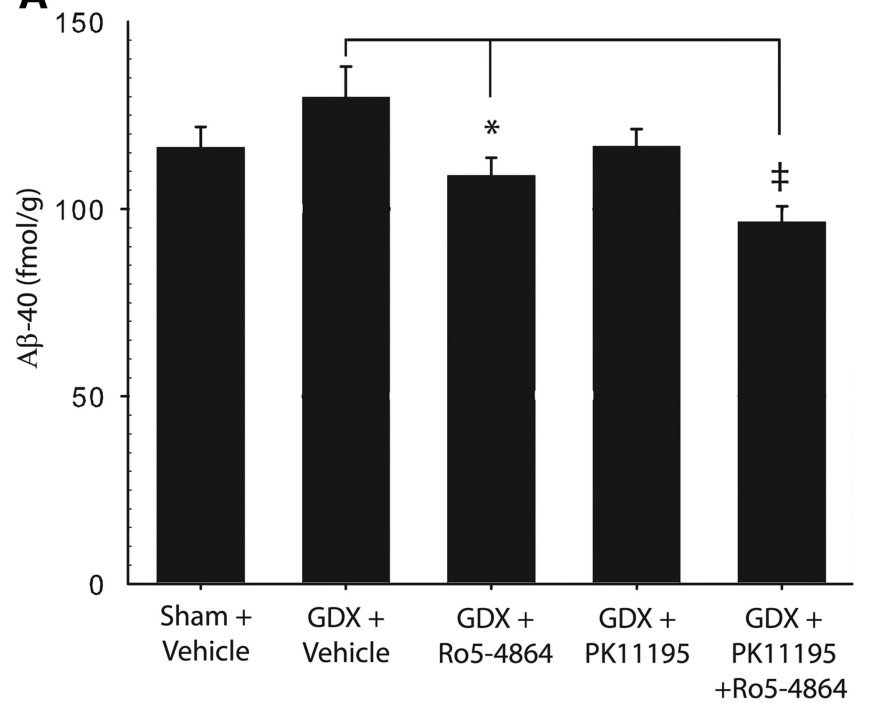

B

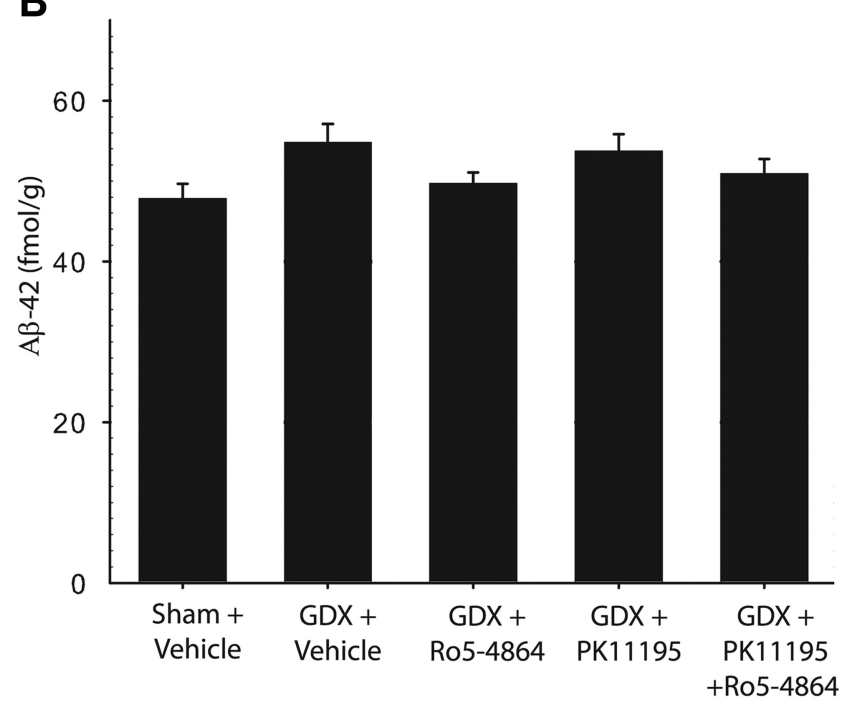

Figure 4. R05-4864 alone or in combination with PK-11195 reduces brain $A \beta$ levels in non-Tg mice. Brain levels of soluble $A \beta X-40(A)$ and $A \beta X-42(B)$ from hemibrain homogenates were assessed by ELLSA in young-adult non-Tg mice treated for 4 weeks with vehicl, R05-4864, PK11195, or R05-4864 + PK11195. Data are mean \pm SEM. ${ }^{*} p<0.02$, compared with GDX + vehicle. ${ }^{\ddagger} p<0.001$, compared with GDX + vehicle. 
demonstrated that TSPO ligands act directly on glia to reduce indices of activation and proliferation (Choi et al., 2002). Chronic neuroinflammation is a significant degenerative factor in $\mathrm{AD}$, and anti-inflammatory drugs have shown some therapeutic promise for AD (Szekely et al., 2004). Although TSPO ligands are under development for in vivo imaging of reactive gliosis in $\mathrm{AD}$, our findings suggest that TSPO ligands may represent not only a marker of neuroinflammation but also a potential antiinflammatory treatment strategy for AD.

The most important outcome of the Ro5-4864 treatment is arguably the marked improvements in functional outcomes, increased working memory performance, and reduced anxiety behaviors in the 3xTgAD mice. Few studies have addressed the effects of TSPO ligands on learning and memory in rodents, although some have reported impaired (Holmes and Drugan, 1991) and others improved (Da Cunha et al., 1991) performance in a passive avoidance task. In both male and female $3 \times \mathrm{TgAD}$ mice, we have reliably observed a strong correlation between $\mathrm{A} \beta$ neuropathology and SAB impairment (Rosario, 2006; Carroll et al., 2010). Therefore, the improved working memory performance observed in the current study is likely related to reduced neuropathology. Consistent with our observations in the 3xTgAD mice, TSPO ligands are potent anxiolytics in both rodents and humans (Rupprecht et al., 2009). Anxiety may indeed be an early indicator of AD in people with mild cognitive impairment (Perry and Hodges, 1999). Thus, TSPO ligands may simultaneously target multiple clinical features of $\mathrm{AD}$, including memory function and anxiety behaviors.

Many new-generation, safe TSPO ligands have been developed for in vivo imaging in humans (Chauveau et al., 2008); however, these ligands may also have a therapeutic potential for the treatment of AD. Because TSPO expression is upregulated in the most severely affected regions of the AD brain, TSPO ligands may selectively target regions most affected by the disease. Together, these findings indicate that TSPO may be a promising target for the development of pleiotropic treatment strategies for the management of $\mathrm{AD}$.

\section{References}

Barreto G, Santos-Galindo M, Diz-Chaves Y, Pernía O, Carrero P, Azcoitia I, Garcia-Segura LM (2009) Selective estrogen receptor modulators decrease reactive astrogliosis in the injured brain: effects of aging and prolonged depletion of ovarian hormones. Endocrinology 150:5010-5015. CrossRef Medline

Carroll JC, Rosario ER, Villamagna A, Pike CJ (2010) Continuous and cyclic progesterone differentially interact with estradiol in the regulation of Alzheimer-like pathology in female $3 \times$ transgenic-Alzheimer's disease mice. Endocrinology 151:2713-2722. CrossRef Medline

Caruso D, Scurati S, Maschi O, De Angelis L, Roglio I, Giatti S, Garcia-Segura LM, Melcangi RC (2008) Evaluation of neuroactive steroid levels by liquid chromatography-tandem mass spectrometry in central and peripheral nervous system: effect of diabetes. Neurochem Int 52:560-568. CrossRef Medline

Caruso D, Barron AM, Brown MA, Abbiati F, Carrero P, Pike CJ, GarciaSegura LM, Melcangi RC (2013) Age-related changes in neuroactive steroid levels in 3xTg-AD mice. Neurobiol Aging 34:1080-1089. CrossRef Medline

Chauveau F, Boutin H, Van Camp N, Dollé F, Tavitian B (2008) Nuclear imaging of neuroinflammation: a comprehensive review of [11C]PK11195 challengers. Eur J Nucl Med Mol Imaging 35:2304-2319. CrossRef Medline

Chen S, Wang JM, Irwin RW, Yao J, Liu L, Brinton RD (2011) Allopregnanolone promotes regeneration and reduces $\beta$-amyloid burden in a preclinical model of Alzheimer's disease. PLoS One 6:e24293. CrossRef Medline

Choi HB, Khoo C, Ryu JK, van Breemen E, Kim SU, McLarnon JG (2002) Inhibition of lipopolysaccharide-induced cyclooxygenase-2, tumor necrosis factor- $\alpha$ and $\left[\mathrm{Ca}^{2+}\right]$ i responses in human microglia by the periph- eral benzodiazepine receptor ligand PK11195. J Neurochem 83:546-555. CrossRef Medline

Cummings BJ, Mason AJ, Kim RC, Sheu PC, Anderson AJ (2002) Optimization of techniques for the maximal detection and quantification of Alzheimer's-related neuropathology with digital imaging. Neurobiol Aging 23:161-170. CrossRef Medline

Da Cunha C, Huang CH, Walz R, Dias M, Koya R, Bianchin M, Pereira ME, Izquierdo I, Medina JH (1991) Memory facilitation by post-training intraperitoneal, intracerebroventricular and intra-amygdala injection of Ro 5-4864. Brain Res 544:133-136. CrossRef Medline

Edison P, Archer HA, Gerhard A, Hinz R, Pavese N, Turkheimer FE, Hammers A, Tai YF, Fox N, Kennedy A, Rossor M, Brooks DJ (2008) Microglia, amyloid, and cognition in Alzheimer's disease: an $\left[{ }^{11} \mathrm{C}\right](\mathrm{R}) \mathrm{PK} 11195-\mathrm{PET}$ and $\left[{ }^{11} \mathrm{C}\right]$ PIB-PET study. Neurobiol Dis 32:412419. CrossRef Medline

Gavioli EC, Duarte FS, Bressan E, Ferrara P, Farges RC, De Lima TC (2003) Antidepressant-like effect of Ro5-4864, a peripheral-type benzodiazepine receptor ligand, in forced swimming test. Eur J Pharmacol 471:21-26. CrossRef Medline

Giatti S, Pesaresi M, Cavaletti G, Bianchi R, Carozzi V, Lombardi R, Maschi O, Lauria G, Garcia-Segura LM, Caruso D, Melcangi RC (2009) Neuroprotective effects of a ligand of translocator protein-18kDa (Ro5-4864) in experimental diabetic neuropathy. Neuroscience 164:520-529. CrossRef Medline

Holmes PV, Drugan RC (1991) Differential effects of anxiogenic central and peripheral benzodiazepine receptor ligands in tests of learning and memory. Psychopharmacology 104:249-254. CrossRef Medline

Ito D, Imai Y, Ohsawa K, Nakajima K, Fukuuchi Y, Kohsaka S (1998) Microglia-specific localisation of a novel calcium binding protein, Iba1. Mol Brain Res 57:1-9. CrossRef Medline

Ji B, Maeda J, Sawada M, Ono M, Okauchi T, Inaji M, Zhang MR, Suzuki K, Ando K, Staufenbiel M, Trojanowski JQ, Lee VM, Higuchi M, Suhara T (2008) Imaging of peripheral benzodiazepine receptor expression as biomarkers of detrimental versus beneficial glial responses in mouse models of Alzheimer's and other CNS pathologies. J Neurosci 28:12255-12267. CrossRef Medline

Lalonde R (2002) The neurobiological basis of spontaneous alternation. Neurosci Biobehav Rev 26:91-104. CrossRef Medline

Middeldorp J, Hol EM (2011) GFAP in health and disease. Prog Neurobiol 93:421-443. CrossRef Medline

Oddo S, Caccamo A, Kitazawa M, Tseng BP, LaFerla FM (2003) Amyloid deposition precedes tangle formation in a triple transgenic model of Alzheimer's disease. Neurobiol Aging 24:1063-1070. CrossRef Medline

Papadopoulos V, Lecanu L (2009) Translocator protein (18 kDa) TSPO: an emerging therapeutic target in neurotrauma. Exp Neurol 219:53-57. CrossRef Medline

Papadopoulos V, Lecanu L, Brown RC, Han Z, Yao ZX (2006a) Peripheraltype benzodiazepine receptor in neurosteroid biosynthesis, neuropathology and neurological disorders. Neuroscience 138:749-756. CrossRef Medline

Papadopoulos V, Baraldi M, Guilarte TR, Knudsen TB, Lacapère JJ, Lindemann P, Norenberg MD, Nutt D, Weizman A, Zhang MR, Gavish M (2006b) Translocator protein $(18 \mathrm{kDa})$ : new nomenclature for the peripheral benzodiazepine receptor based on its structure and molecular function. Trends Pharmacol Sci 27:402-409. CrossRef Medline

Perry RJ, Hodges JR (1999) Attention and executive deficits in Alzheimer's disease: a critical review. Brain 122:383-404. CrossRef Medline

Ramsden M, Nyborg AC, Murphy MP, Chang L, Stanczyk FZ, Golde TE, Pike CJ (2003) Androgens modulate $\beta$-amyloid levels in male rat brain. J Neurochem 87:1052-1055. CrossRef Medline

Rosario ER, Carroll JC, Oddo S, LaFerla FM, Pike CJ. (2006) Androgens regulate the development of neuropathology in a triple transgenic mouse model of Alzheimer's disease. J Neurosci 26:13384-13389. CrossRef Medline

Rosario ER, Carroll J, Pike CJ (2010) Testosterone regulation of Alzheimerlike neuropathology in male 3xTg-AD mice involves both estrogen and androgen pathways. Brain Res 1359:281-290. CrossRef Medline

Rosario ER, Chang L, Head EH, Stanczyk FZ, Pike CJ (2011) Brain levels of sex steroid hormones in men and women during normal aging and in Alzheimer's disease. Neurobiol Aging 32:604-613. CrossRef Medline

Rupprecht R, Rammes G, Eser D, Baghai TC, Schüle C, Nothdurfter C, Troxler T, Gentsch C, Kalkman HO, Chaperon F, Uzunov V, McAllister KH, 
Bertaina-Anglade V, La Rochelle CD, Tuerck D, Floesser A, Kiese B, Schumacher M, Landgraf R, Holsboer F, et al. (2009) Translocator protein $(18 \mathrm{kD})$ as target for anxiolytics without benzodiazepine-like side effects. Science 325:490-493. CrossRef Medline

Rupprecht R, Papadopoulos V, Rammes G, Baghai TC, Fan J, Akula N, Groyer G, Adams D, Schumacher M (2010) Translocator protein (18 $\mathrm{kDa}$ ) (TSPO) as a therapeutic target for neurological and psychiatric disorders. Nat Rev Drug Discov 9:971-988. CrossRef Medline

Szekely CA, Thorne JE, Zandi PP, Ek M, Messias E, Breitner JC, Goodman SN (2004) Nonsteroidal anti-inflammatory drugs for the prevention of Alzheimer's disease: a systematic review. Neuroepidemiology 23: 159-169. CrossRef Medline

Torres SR, Fröde TS, Nardi GM, Vita N, Reeb R, Ferrara P, Ribeiro-do-Valle RM, Farges RC (2000) Anti-inflammatory effects of peripheral benzodiazepine receptor ligands in two mouse models of inflammation. Eur J Pharmacol 408:199-211. CrossRef Medline

Vallée M, Mayo W, Darnaudéry M, Corpéchot C, Young J, Koehl M, Le Moal M, Baulieu EE, Robel P, Simon H (1997) Neurosteroids: deficient cognitive performance in aged rats depends on low pregnenolone sulfate levels in the hippocampus. Proc Natl Acad Sci U S A 94:1486514870. CrossRef Medline
Veenman L, Gavish M (2000) Peripheral-type benzodiazepine receptors: their implication in brain disease. Drug Dev Res 50:355-370. CrossRef

Veiga S, Azcoitia I, Garcia-Segura LM (2005) Ro5-4864, a peripheral benzodiazepine receptor ligand, reduces reactive gliosis and protects hippocampal hilar neurons from kainic acid excitotoxicity. J Neurosci Res 80:129-137. CrossRef Medline

Walsh DM, Selkoe DJ (2007) A $\beta$ oligomers: a decade of discovery. J Neurochem 101:1172-1184. CrossRef Medline

Weibel ER (1979) Stereological methods, Vol 1. Practical methods for biological morphometry. London: Academic.

Yasuno F, Ota M, Kosaka J, Ito H, Higuchi M, Doronbekov TK, Nozaki S, Fujimura Y, Koeda M, Asada T, Suhara T (2008) Increased binding of peripheral benzodiazepine receptor in Alzheimer's disease measured by positron emission tomography with $\left[{ }^{11} \mathrm{C}\right]$ DAA1106. Biol Psychiatry 64: 835-841. CrossRef Medline

Yue X, Lu M, Lancaster T, Cao P, Honda S, Staufenbiel M, Harada N, Zhong Z, Shen Y, Li R (2005) Brain estrogen deficiency accelerates Ab plaque formation in an Alzheimer's disease animal model. Proc Natl Acad Sci U S A 102:19198-19203. CrossRef Medline 